\title{
DOPAMINE METABOLISM FOLLOWING IRREVERSIBLE INACTIVATION OF AROMATIC AMINO ACID DECARBOXYLASE IN RETINA ${ }^{1}$
}

\author{
DAVID PARKINSON, ${ }^{*}$ ROBERT BAUGHMAN, $\ddagger$ RICHARD H. MASLAND, $\ddagger$ AND \\ ROBERT R. RANDO*, \\ Departments of *Pharmacology and $\ddagger$ Neurobiology, Harvard Medical School, Boston, Massachusetts 02115
}

\begin{abstract}
The effects of an intravitreal injection of $\alpha$-fluoromethyldopa, an irreversible mechanism-based inactivator of aromatic $\mathrm{t}$-amino acid decarboxylase, on the retinal dopamine content of light-adapted chicks and rabbits have been examined. A single administration of $10 \mathrm{nmol}$ of $\alpha$-fluoromethyldopa totally inactivates aromatic L-amino acid decarboxylase within $2 \mathrm{hr}$ in vivo in rabbits. By 4 to $6 \mathrm{hr}$, the level of dihydroxyphenylalanine increased 7-fold and the levels of dopamine and dihydroxyphenylacetic acid fell by $90 \%$. With an injection of $50 \mathrm{nmol}$, similar results were observed in chicks. The levels of dihydroxyphenylacetic acid began to fall soon after injection when significant (30 to $40 \%$ ) amounts of dopamine were still present. These results are discussed in relation to the use of tissue dihydroxyphenylacetic acid levels to indicate the level of dopaminergic neuronal activity or dopamine synthesis. Recovery by the retinae of both species was shown by the return of aromatic L-amino acid decarboxylase activity and the resynthesis of dopamine.
\end{abstract}

A considerable amount of information about the functions of neurotransmitters in the peripheral and central nervous systems has been obtained by studying the effects of drugs which interfere with their synthesis or degradation. Interpretation of these results can be complicated by drug actions other than those desirable for the particular purpose in mind. For example, $p$-chlorophenylalanine (PCPA) ${ }^{3}$ is used to block tryptophan hydroxylase in vivo and the resultant decline in tissue 5hydroxytryptamine (5-HT) is used to give a measure of the rate of turnover (Kore and Weissman, 1966). However, PCPA also will interfere with catecholamine biosynthesis (Sanders-Bush et al., 1974). Similarly, brocresine (NSD 1055) is used to inhibit aromatic L-amino acid decarboxylase (L-AAAD) to study the rate of synthesis

\footnotetext{
${ }^{1}$ This work was supported by National Institutes of Health Grants EY03624 (R. R. R.), EY00606, EY03502 (R. B.), and EY01075 (R. H. M.), a Sloan Foundation grant (R. B.), and a Research Career Development award (R. H. M.). D. P. thanks the Wellcome Trust for a travel grant. We wish to thank Dr. T. Weisel for helpful discussions. (S)- $\alpha$ Fluoromethyldopa was a gift from Dr. J. Kollonitsch of Merck, Sharp and Dohme Research Laboratories.

${ }^{2}$ To whom correspondence should be addressed at Department of Pharmacology, Harvard Medical School, 250 Longwood Avenue, Boston, MA 02115.

${ }^{3}$ The abbreviations used are: L-AAAD, aromatic L-amino acid decarboxylase; DOPA, dihydroxyphenylalanine; DOPAC, dihydroxyphenylacetic acid; EDTA, ethylenediaminetetra-acetate; $\alpha$-FMD, $\alpha$ fluoromethyldopa; 5-HT, 5-hydroxytryptamine; MAO, monoamine oxidase; PCPA, p-chlorophenylalanine; Tris, tris(hydroxymethyl)aminomethane.
}

and turnover of the biogenic amine neurotransmitters, but it also inhibits histamine biosynthesis (Moles and Sheperd, 1973).

Mechanism-based irreversible inactivators largely overcome the problem of specificity (Rando, 1974). These inactivators are substrates for the target enzyme, but they also contain latent reactive groupings within their structure. It is not until the enzyme metabolizes the inactivator that the reactive grouping is unmasked and the enzyme is inactivated. $(S)-\alpha$-Fluoromethyldopa $(\alpha$ FMD) is an inhibitor of this type which inactivates $\mathrm{L}$ AAAD (Kollonitsch et al., 1978).

Clearly, inhibition of L-AAAD by $\alpha$-FMD will block the formation of all catecholamines and indoleamines since this enzyme is common to all of their biosynthetic pathways (McGeer and McGeer, 1973). This complication is less important in tissues where only one of these amines is present as a neurotransmitter.

Of the biogenic amines that appear to act as neurotransmitters in the brain, only for dopamine is there strong evidence for a role in the vertebrate retina. With retinae from various species, it has been shown that dopamine is present in appreciable quantities, is synthesized by the intact retina, and is released by a $\mathrm{Ca}^{2+}$. dependent mechanism (see Ehinger, 1976; Starr, 1977 for reviews). In addition, dopamine and some of the drugs which affect its actions have effects on the activity of some retinal neurons (Ames and Pollen, 1969). In the rabbit and chick retinae, histochemical methods have localized dopamine to a defined subset of amacrine cells (Ehinger, 1967; Haggendal and Malmfors, 1965). Norepi- 
nephrine has not been found in significant amounts in the retinae of those species so far studied (Haggendal and Malmfors, 1965; Nichols et al., 1967). There is, however, some evidence to suggest a neurotransmitter function for 5-HT in chick and bovine retina (Suzuki et al., 1977; Thomas and Redburn, 1979) but not in rabbit (Floren and Hansson, 1980).

The retina is an unusually favorable tissue for investigations of neurotransmitter function and metabolism. It is a relatively simple structure and its morphology has been much studied by both light and electron microscopy. Because it is located at the periphery, it can be removed with little damage for incubation in vitro or selectively exposed to test compounds in vivo by their injection into the eye. Finally, the retina can be activated by natural stimuli and thus provides both a means of identifying the effects of neurotransmitter release in physiological experiments and of controlling the demand for neurotransmitters in biochemical ones. We therefore sought to characterize the effects of $\alpha$-FMD on retinal L-AAAD and dopamine. We report that this compound rapidly inactivates L-AAAD when intravitreally administered to rabbits and chicks and demonstrate the resultant dramatic effect on the retinal content of dopamine, dihydroxyphenylalanine (DOPA), and dihydroxyphenylacetic acid (DOPAC).

\section{Materials and Methods}

Young adult New Zealand white rabbits (2 to $3 \mathrm{~kg}$ ) were obtained from Margarets Home Farm, Attleboro, MA and 12-day-old white Ieghorn chicks were obtained from Spafas, Inc., Norwich, CT. All animals were exposed to normal fluorescent room lighting for at least $16 \mathrm{hr}$ before and throughout any experiment. Animals were injected intraocularly under ether anesthesia with $10 \mu \mathrm{l}$ of drug solution dissolved in $0.9 \%(\mathrm{w} / \mathrm{v})$ saline which had been sterilized by membrane filtration $(0.45-\mu \mathrm{m}$ pores $)$. Rabbits were killed by cervical dislocation and chicks by decapitation. The eyes were enucleated, the cornea was cut away with a razor blade, and the vitreous body was removed. The eyecup was cut into two portions through the optic nerve and the half-retinae were teased out under a dissecting microscope. The tissue was stored at $-70^{\circ} \mathrm{C}$ in preweighed $1.5-\mathrm{ml}$ microcentrifuge tubes until required for assay.

Dopamine, its metabolites, and $\alpha$-FMD were assayed by a combination of high pressure liquid chromatography and electrochemical detection after isolation of catechols on alumina (Mefford et al., 1980). Briefly, half-retinae were sonicated in cold $0.1 \mathrm{M}$ perchloric acid $(100 \mu \mathrm{l}$ for chick and $200 \mu \mathrm{l}$ for rabbit) containing $0.4 \mathrm{~mm}$ sodium bisulfite, $0.1 \mathrm{~mm}$ disodium EDTA, and $3 \mathrm{ng}$ of dihydroxybenzylamine as the internal standard and centrifuged at $27,000 \times g$ for $30 \mathrm{~min}$. To $100 \mu \mathrm{l}$ of the supernatant, 10 $\mathrm{mg}$ of acid-washed alumina and $1 \mathrm{ml}$ of $0.5 \mathrm{~m}$ Tris- $\mathrm{HCl}$, $\mathrm{pH} 8.6$, were added and the $1.5-\mathrm{ml}$ microcentrifuge tubes were shaken mechanically by inversion for $10 \mathrm{~min}$. The tubes were centrifuged, the supernatant was aspirated off, and the alumina was washed with two $1-\mathrm{ml}$ aliquots of distilled water. Catechols were eluted by agitation of the alumina with $100 \mu \mathrm{l}$ of $0.1 \mathrm{~N} \mathrm{HCl}$ for $10 \mathrm{~min}$ and then centrifuged. Usually $30 \mu \mathrm{l}$ of the eluate was injected onto the liquid chromatograph. The mixture was resolved by reverse phase ion pair chromatography on a RP-18 guard column $(3 \times 0.46 \mathrm{~cm}$, Brownlee $)$ and $\mu$ Bondapak $\mathrm{C}_{18}(30$ $\times 0.4 \mathrm{~cm}$, Waters) analytical column through which was pumped $50 \mathrm{~mm}$ sodium phosphate, $\mathrm{pH} 3.5$, containing 0.1 $\mathrm{gm} /$ liter of sodium heptane sulfonic acid, $8 \%(\mathrm{v} / \mathrm{v})$ methanol, and $0.1 \mathrm{mM}$ disodium EDTA at $1 \mathrm{ml} / \mathrm{min}$. Catechols in the eluate were assayed electrochemically with a TL3 flow cell packed with carbon paste (silicone grease base) and connected to an LC-3 controller (Bioanalytical Systems). The working electrode was operated at $0.60 \mathrm{~V}$. Authentic samples of DOPA, $\alpha$-FMD, dopamine, and DOPAC were carried through the extraction procedure with the internal standard added. Tissue levels of a compound were computed by the internal standard-peak height ratio method and expressed as nanograms per gm of tissue, wet weight. The limits of sensitivity as given by a peak height of 5 times base line noise were 30 to $50 \mathrm{pg}$ per injection for DOPAC and 20 to $25 \mathrm{pg}$ for other catechols. The efficiency of extraction was about $60 \%$ for the internal standard, 37\% for DOPA and $\alpha$-FMD, $40 \%$ for dopamine, and $25 \%$ for DOPAC.

L-AAAD activity in retinal homogenates was assayed by measuring the release of ${ }^{14} \mathrm{CO}_{2}$ from $\mathrm{L}-\left[1-{ }^{14} \mathrm{C}\right] \mathrm{DOPA}$. Half-retinae of either species were sonicated in $200 \mu \mathrm{l}$ of cold $5 \mathrm{~mm}$ sodium phosphate, at $\mathrm{pH} 7$, containing $10 \mathrm{~mm}$ 2-mercaptoethanol and centrifuged at $27,000 \times g$ for 30 min. Aliquots of the supernatant were dispensed into 6 $\times 50 \mathrm{~mm}$ glass test tubes on ice and made up to $50 \mu \mathrm{l}$ with homogenization buffer. To this was added $50 \mu \mathrm{l}$ of a solution containing $0.1 \mathrm{~m}$ sodium phosphate, $\mathrm{pH} 7.0,56$ $\mu \mathrm{M}$ pyridoxal 5-phosphate, $20 \mathrm{~mm}$ 2-mercaptoethanol, 1 $\mathrm{mM}$ L-DOPA, and $2 \mu \mathrm{Ci} / \mathrm{ml}$ of $\mathrm{DL}-\left[1-{ }^{14} \mathrm{C}\right] \mathrm{DOPA}$. The tubes were placed on 20 -ml glass scintillation vials containing $600 \mu \mathrm{l}$ of $1 \mathrm{~N} \mathrm{NaOH}$ and the vials then were closed with rubber septum caps. The vials were incubated for 1 $\mathrm{hr}$ at $37^{\circ} \mathrm{C}$ and then $100 \mu \mathrm{l}$ of $10 \%$ trichloroacetic acid was injected into the assay mixture through the septum. The vials were incubated further for $1 \mathrm{hr}$ at $37^{\circ} \mathrm{C}$ and allowed to cool to room temperature. Then $500 \mu \mathrm{l}$ of the $\mathrm{NaOH}$ was removed for the determination of absorbed ${ }^{14} \mathrm{C}$ content by liquid scintillation spectrometry after addition of $5 \mathrm{ml}$ of Aquasol (New England Nuclear). To ensure good emulsion formation with the Aquasol, the alkali was partly neutralized by addition of $50 \mu \mathrm{l}$ of $3 \mathrm{~N}$ $\mathrm{HCl}$. Under these conditions, the assay was linear with time up to $1 \mathrm{hr}$ and with protein up to $500 \mu \mathrm{g}$. Enzyme activity was expressed as nanomoles of ${ }^{14} \mathrm{CO}_{2}$ formed per $\mathrm{mg}$ of protein per $\mathrm{hr}$ after allowing for the fact that $50 \%$ of the radioactivity in the substrate was in the $\mathrm{D}$ isomer and therefore was not available to L-AAAD.

Protein was measured by the method of Lowry et al. (1951) with bovine serum albumin as standard.

\section{Results}

Preliminary experiments indicate that an injection of 10 to $15 \mathrm{nmol}$ of $\alpha$-FMD into a rabbit eye of about $1.5 \mathrm{ml}$ volume was the minimum dose to inhibit L-AAAD in retina maximally within $4 \mathrm{hr}$. Assuming uniform dispersal throughout the posterior eye chamber, this gives a concentration of about $7 \times 10^{-6} \mathrm{M}$, which agrees well with the concentration, $10^{-5} \mathrm{M}$, required to give maximal in- 
hibition in retinal homogenates (Fig. 1). The short term effects of an injection of $10 \mathrm{nmol}$ of $\alpha$-FMD are shown in detail in Figures 2 and 3. Retinal levels of $\alpha$-FMD did not reach a maximum value until $4 \mathrm{hr}$ after injection and thereafter fell exponentially with a half-time of about 4 $\mathrm{hr}$. Within $2 \mathrm{hr}$, L-AAAD activity had been reduced to blank values and, at $24 \mathrm{hr}$, there was no measurable recovery of the enzyme (Fig. 2). Dopamine levels were reduced by $70 \%$ within $2 \mathrm{hr}$ and by $95 \%$ at $8 \mathrm{hr}$ (Fig. 3). The level of dopamine appeared to begin to recover at 24 $\mathrm{hr}$, but the value at this time point is not significantly different from the values at the preceding two time points. Calculated from the data for 2 and $4 \mathrm{hr}$ after $\alpha$ FMD, the half-life of dopamine in this experiment was $41 \mathrm{~min}$. Levels of the dopamine metabolite DOPAC were depleted in a similar manner after $\alpha$-FMD treatment (Fig. 3). On the other hand, the retinal content of DOPA, which is the normal substrate for L-AAAD, underwent an apparently linear increase that plateaued $4 \mathrm{hr}$ after the $\alpha$-FMD injection at about 7 times the control values. In long term experiments, it was found that it took up to 16 days for L-AAAD levels to return to normal after total inhibition by $\alpha$-FMD. Assuming that L-AAAD is degraded by a first order process and synthesized by a zero order mechanism, this enzyme has a half-life of about 4 days in the retina. In these experiments, dopamine levels began to approach control values after $48 \mathrm{hr}$, when the L-AAAD activity had reached only 15 to $20 \%$ of control.

That the levels of the dopamine returned to normal after exposure of the retina to $\alpha$-FMD is evidence that the cells containing dopamine were not destroyed by the experimental treatment. To look for possible morphological changes, we injected $\alpha$-FMD into rabbit eyes three times at intervals of 3 days. One week after the last

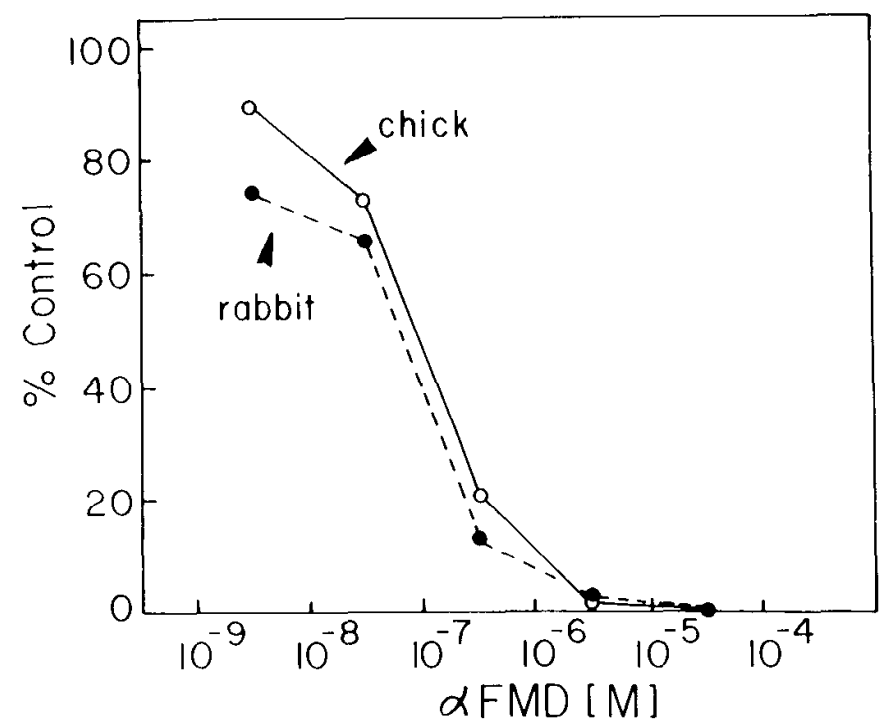

Figure 1. The effect of increasing concentration of $\alpha$-FMD on the L-AAAD activity of rabbit and chick retinal homogenates. Aliquots of homogenate were incubated for $30 \mathrm{~min}$ at $37^{\circ} \mathrm{C}$ with the indicated concentrations of $\alpha$-FMD before adding L-DOPA (final concentration, $0.5 \mathrm{~mm}$ ) and assaying for residual L-AAAD activity. The results are expressed as the percentage of the enzyme activity observed when incubated in the absence of the inhibitor.

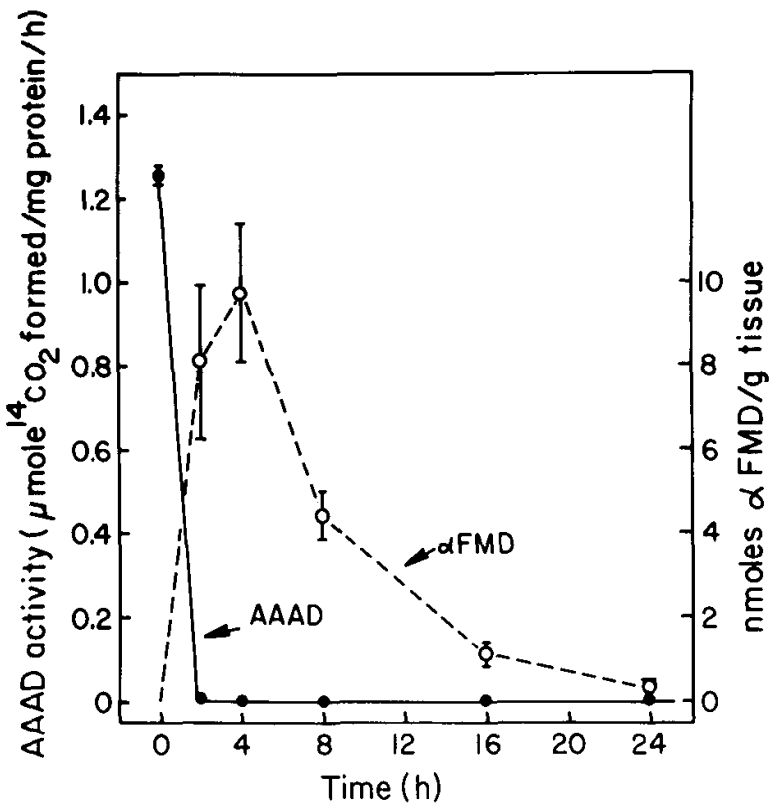

Figure 2. The retinal content of $\alpha$-FMD after a single intravitreal injection of $10 \mathrm{nmol}$ and the effects on L-AAAD activity in young adult rabbits. Each point is the mean ( \pm SEM) of data from four retinae. The data for L-AAAD activity for 2 to $24 \mathrm{hr}$ after the injection was not distinguishable from the blank value. Animals were light-adapted for $24 \mathrm{hr}$ before the start of the experiment.

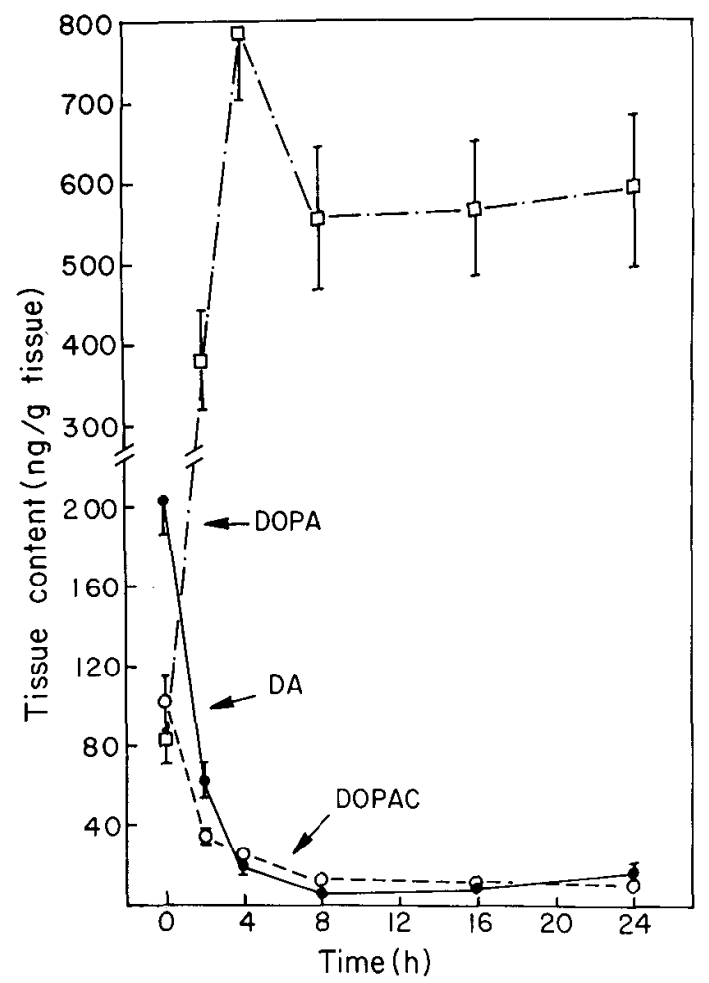

Figure 3. The effect of a $10-\mathrm{nmol}$ injection of $\alpha$-FMD (intravitreally) on the retinal content of dopamine ( $D A)$, DOPA, and DOPAC in young adult rabbits. Each point is the mean $( \pm$ SEM) of data from the same four retinae from which Figure 1 was derived. 
injection, the retinae were removed, fixed in glutaraldehyde, dehydrated in graded ethanols, and embedded in glycol methacrylate resin. The structure of the treated retinae was indistinguishable, at the level of light microscopy, from that of untreated controls.

In the chick, an intravitreal injection of $50 \mathrm{nmol}$ of $\alpha$ FMD was the minimum dose that would inhibit retinal L-AAAD totally within $2 \mathrm{hr}$. The $\alpha$-FMD was eliminated more rapidly than that from rabbit retina, with a halflife of about $1 \mathrm{hr}$. Figure 4 shows the short term effects of this dose on dopamine content in chick retina and the activity of L-AAAD. Retinal dopamine levels were reduced by $85 \% 2 \mathrm{hr}$ after this treatment; within $4 \mathrm{hr}$, the levels were at the limits of sensitivity of the assay (i.e., about $300 \mathrm{pg} / \mathrm{retina}$ ). The approximate half-time for this loss of dopamine was $1 \mathrm{hr}$. The recovery of dopamine synthesis by chick retina was studied after two injections of $50 \mathrm{nmol}$ of $\alpha$-FMD as shown in Figure 5. Chick retinal L-AAAD was beginning to reappear $12 \mathrm{hr}$ after the last injection and then steadily increased in activity up to $35 \%$ of untreated values $36 \mathrm{hr}$ later. From these data, a half-life of about 3 days was calculated for L-AAAD in chick retina. At 12 to $16 \mathrm{hr}$, L-AAAD activity, dopamine, and DOPAC again could be detected. By $24 \mathrm{hr}$, dopamine and DOPAC levels had reached $50 \%$ of control values when only $10 \%$ of L-AAAD had recovered, and at this time, L-DOPA had fallen from 10- to 2 -fold of untreated levels. The retinal dopamine content had reached untreated values after $48 \mathrm{hr}$. The levels of DOPAC paralleled the increase in retinal dopamine up to $36 \mathrm{hr}$ and then appeared to reach a steady value at about $60 \%$ of control.

\section{Discussion}

Our results show that, after inhibition of synthesis with $\alpha$-FMD, retinal dopamine levels can be reduced by greater than $90 \%$ within $4 \mathrm{hr}$ in light-adapted chicks and rabbits. In chicks, the dopamine level was reduced from

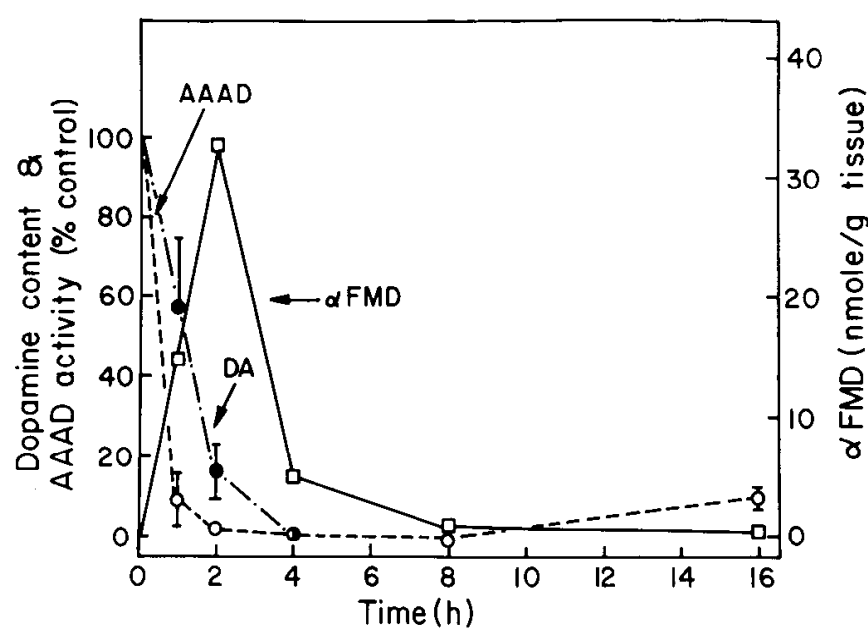

Figure 4. The effect of a 50-nmol injection of $\alpha$-FMD (intravitreally) on the retinal content of $\alpha$-FMD and dopamine $(D A)$ and on L-AAAD activity in 12-day-old chicks. Each point is the mean of data from four animals except that for $\alpha$-FMD which is the mean of data from two animals. The animals were light-adapted for $24 \mathrm{hr}$ before the experiment.

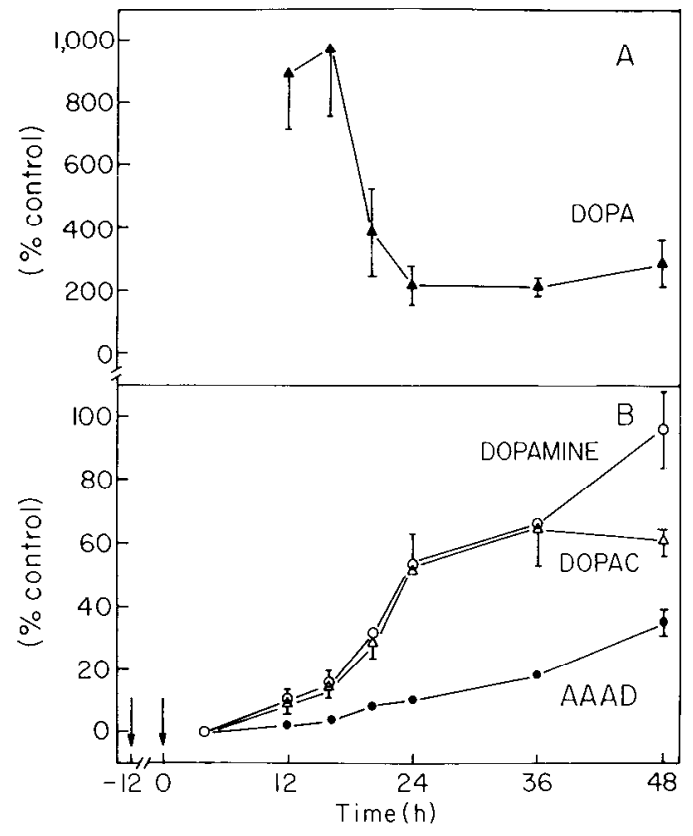

Figure 5. The recovery of L-AAAD activity and dopamine synthesis after $\alpha$-FMD. Light-adapted 12-day-old chicks received intravitreal injections of $50 \mathrm{nmol}$ of $\alpha$-FMD $12 \mathrm{hr}$ before and at the beginning of the experiment. Each point is the mean ( \pm SEM) of data from four animals expressed as a percentage of the result for the untreated contralateral eye. Animals were kept in normal room light throughout the experiment. In panel $A$, the data for DOPA are presented. In panel $B$, the data for dopamine, DOPAC, and AAAD recovery are presented.

control levels of 100 to $120 \mathrm{ng} / \mathrm{gm}$ of tissue to the limits of sensitivity of the assay (about 2 to $3 \mathrm{ng} / \mathrm{gm}$ of tissue). Rabbit retinae contain about $200 \mathrm{ng}$ of dopamine/gm of tissue. After treatment with $\alpha$-FMD, this level fell to $10 \%$ of control values ( $20 \mathrm{ng} / \mathrm{gm}$ of tissue) after $4 \mathrm{hr}$ and to about $5 \%$ ( 5 to $10 \mathrm{ng} / \mathrm{gm}$ of tissue) after 8 and $16 \mathrm{hr}$. The small amount of dopamine may represent synthesis by uninhibited L-AAAD beyond the limits of the in vitro assay. The recovery of dopaminergic function in vivo after treatment with $\alpha$-FMD should depend upon the rate of de novo synthesis of L-AAAD protein. In chick, recovery of dopamine synthesis as indicated by the reduction of the elevated DOPA levels as well as increased dopamine content was apparent within $16 \mathrm{hr}$ of the treatment with $\alpha$-FMD when only a small proportion of L-AAAD activity had returned. This confirms that, in vivo, this enzyme is not the rate-limiting step in the synthesis of dopamine (Iuvone et al., 1978). In the experiments with rabbits, dopamine levels had not recovered $24 \mathrm{hr}$ after $\alpha$-FMD, but recovery was observed at later times. The slower recovery of dopamine in rabbit retina compared to that in chick retina may result from several factors. The rate of elimination of $\alpha$-FMD from the retina, and therefore probably from the intravitreal injection site, was about 4 times faster in chicks than in rabbits. This may be due to the smaller volume of the eye in 12-day-old chicks $(\sim 0.5 \mathrm{ml})$ compared to that in young adult rabbits $(\simeq 1.5 \mathrm{ml})$. This would lengthen the time during which sufficient $\alpha$-FMD would be present in the retina to inhibit newly synthesized L-AAAD in rab- 
bits. Secondly, the rate of synthesis of L-AAAD was slightly faster in chicks and, in the early phase of recovery, this would speed transmitter recovery.

The observation that dopamine synthesis recovers in both species along with L-AAAD activity suggests that the depletion of dopamine after $\alpha$-FMD treatment is the result of a specific lesion (i.e., inhibition of L-AAAD) and is not due to some cytotoxic effect. This is supported further by the unchanged retinal morphology observed in the light microscope when rabbits were repeatedly injected intravitreally with $\alpha$-FMD.

Metabolism of dopamine in nervous tissues can lead to the formation of two acidic metabolites. DOPAC is formed by the action of monoamine oxidase (MAO) on dopamine while homovanillic acid (4-hydroxy-3-methoxyphenylacetic acid) is produced by the combined action of MAO and catechol $O$-methyltransferase (Sharman, 1973). It has been suggested that, in the corpus striatum, DOPAC and homovanillic acid reflect intraneuronal and extraneuronal metabolism of dopamine, respectively (Roffler-Tarlov et al., 1971). The tissue levels of these metabolites have been used, therefore, as indices of the amount of dopaminergic neuronal activity (RofflerTarlov et al., 1971; Walters and Roth, 1972; Westerink and Korf, 1976; Beart and Gundlach, 1980). The basis of this approach is the assumption that the cytoplasmic level of dopamine in the neuron is low except when large amounts of dopamine are being recaptured after periods of high activity. The level of cytoplasmic dopamine then would reflect the rate of dopamine release, and since MAO can act only on the cytoplasmic dopamine, the level of DOPAC would be related directly to the neuron's activity.

We observed that, after treatment with $\alpha$-FMD, the retina's content of DOPAC fell (and rose again) in parallel with its content of dopamine: $2 \mathrm{hr}$ after treatment with $\alpha$-FMD, dopamine stores had been depleted by $75 \%$ and retinal DOPAC levels were reduced by about $70 \%$. What does this mean for the relation between DOPAC and activity? Classically, it has been thought that the packaging of neurotransmitter into vesicles provides a mechanism by which neurotransmitter release can remain constant in the face of moderate changes in the presynaptic content of neurotransmitter (Potter, 1970). This has been supported by experiments in which tissue amine levels were reduced by reserpine; it appears that severe depletion $(>80 \%)$ of the transmitter is necessary to impair neuronal transmission (Muscholl and Vogt, 1958; Carlsson, 1966; Gillespie and McGrath, 1974). If this is correct, the neurotransmitter release in our experiments still should have been occurring at near normal levels when dopamine had been only partly depleted and, therefore, DOPAC levels should not have fallen.

An explanation for our finding is that there are, in fact, two sources of the intracellular dopamine on which MAO acts-re-uptake after release and new synthesis. The parallel rise and fall of dopamine and DOPAC content after $\alpha$-FMD treatment suggests that DOPAC more accurately reflects the rate of synthesis of dopamine than the rate of its release. Since increased activity leads to increased transmitter synthesis in dopaminergic neurons (Murrin and Roth, 1976), the use of DOPAC levels as a measure of neuronal function is thus not necessarily invalidated if our interpretation is correct. It is possible, in addition, that more than $20 \%$ of neuronal stores are necessary to maintain the normal level of neurotransmitter release in the dopaminergic neurons of the retina. An investigation of the effects of tyrosine hydroxylase inhibitors on the tissue content of DOPAC and homovanillic acid should help to resolve this problem.

In conclusion, our experiments have shown that inhibition of L-AAAD by $\alpha$-FMD produces a rapid and dramatic depletion of retinal dopamine and DOPAC in lightadapted rabbits and chicks. The tissues recover from the effects of $\alpha$-FMD when new enzyme protein is synthesized. The use of $\alpha$-FMD as a tool to investigate the synthesis and turnover of indoleamine neurotransmitter in chick retina is described in the accompanying paper (Parkinson and Rando, 1981).

\section{References}

Ames, A., and D. A. Pollen (1969) Neurotransmission in central nervous tissue: A study of isolated rabbit retina. J. Neurophysiol. 32: 424-442.

Beart, P. M., and A. L. Gundlach (1980) 3,4-Dihydroxyphenylacetic acid (DOPAC) and the rat mesolimbic dopaminergic pathway: Drug effects and evidence for somatodendritic mechanisms. Br. J. Pharmacol. 69: 241-247.

Carlsson, A. (1966) Drugs which block the storage of 5-hydroxytryptamine and related amines. In Handbook of Experimental Pharmacology, O. Eichler and A. Farah, eds., Vol. XIX, pp. 529-578, Springer-Verlag, Berlin.

Ehinger, B. (1967) Adrenergic nerves in the avian eye and ciliary ganglion. Z. Zellforsch. Mikrosk. Anat. 82: 577-588.

Ehinger, B. (1976) Biogenic amines as transmitters in the retina. In Transmitters in the Visual Process, S. L. Bonting, ed., pp. 145-163, Pergamon Press, Oxford.

Floren, I., and H. C. Hansson (1980) Investigations into whether 5 -hydroxytryptamine is a neurotransmitter in the retina of rabbit and chicken. Invest. Ophthalmol. Vis. Sci. 19: 117-125.

Gillespie, J. S., and S. C. McGrath (1974) The effect of pithing and nerve stimulation on the depletion of noradrenaline by reserpine in the rat amococcygeus muscle and vas deferens. Br. J. Pharmacol. 52: 585-590.

Haggendal, J., and T. Malmfors (1965) Identification and cellular localization of the catecholamines in the retina and choroid of the rabbit. Acta Physiol. Scand. 64: 58-66.

Iuvone, P. M., C. L. Galli, C. K. Garrison-Gund, and N. H. Neff (1978) Light stimulates tyrosine hydroxylase activity and dopamine synthesis in retinal amacrine neurons. Science 202: 901-902.

Kollonitsch, J., A. A. Patchett, S. Marburg, A. L. Maycock, L. M. Perkins, G. A. Doldouras, D. E. Duggan, and A. D. Aster (1978) Selective inhibitors of the biosynthesis of aminergic neurotransmitters. Nature 274: 906-908.

Kore, B. K., and A. Weissman (1966) $p$-Chlorophenylalanine: A specific depletor of brain serotonin. J. Pharmacol. Exp. Ther. 154: 499-516.

Lowry, O. H., N. J. Rosebrough, A. L. Farr, and R. J. Randall (1951) Protein measurement with the Folin phenol reagent. J. Biol. Chem. 193: 265-275.

McGeer, P. L., and E. G. McGeer (1973) Neurotransmitter synthetic enzymes. Prog. Neurobiol. 2: 71-117.

Mefford, I. N., M. Gilberg, and J. D. Barchas (1980) Simultaneous determination of catecholamines and unconjugated DOPAC in brain tissue by ion-pairing reverse HPLC with electrochemical detection. Anal. Biochem. 104: 469-472.

Moles, K. H., and D. M. Sheperd (1973) The inhibition of 
histamine formation in vivo. J. Pharm. Pharmacol. 25: 609613.

Murrin, L. C., and R. H. Roth (1976) Dopaminergic neurons: Effects of electrical stimulation on dopamine biosynthesis. Mol. Pharmacol. 12: 463-475.

Muscholl, F., and M. Vogt (1958) The action of reserpine on the peripheral sympathetic system. J. Physiol. (Lond.) 141: 132-155.

Nichols, C. W., D. Jacobowitz, and M. Hottenstein (1967) The influence of light and dark on the catecholamine content of the retina and choroid. Invest. Ophthalmol. Vis. Sci. 6: 642646.

Parkinson, D., and R. R. Rando (1981) Evidence for a neurotransmitter role for 5 -hydroxytryptamine in chick retina. J. Neurosci. 1: 1211-1217.

Potter, L. T. (1970) Synthesis, storage and release of $\left({ }^{14} \mathrm{C}\right)$ acetylcholine in isolated rat diaphragm muscles. J. Physiol. (Lond.) 206: 145-166.

Rando, R. R. (1974) The chemistry and enzymology of $K_{\text {cat }}$ inhibitors. Science 185: 320-324.

Roffler-Tarlov, S., D. F. Sharman, and P. Tegerdine (1971) 3,4Dihydroxyphenylacetic acid in the mouse striatum: A reflec- tion of intra- and extra-neuronal metabolism of dopamine? Br. J. Pharmacol. 42: 343-351.

Sanders-Bush, E., D. A. Gallager, and F. Sulser (1974) On the mechanism of brain 5 -hydroxytryptamine depletion by $p$ chloroamphetamine and related drugs and the specificity of their action. Adv. Biochem. Psychopharmacol. 10: 185-194.

Sharman, D. F. (1973) The catabolism of catecholamines. Recent studies. Br. Med. Bull. 29: 110-115.

Starr, M. S. (1977) Prospective neurotransmitters in vertebrate retina. Essays Neurochem. Neuropharmacol. 2: 151-174.

Suzuki, O., E. Noguchi, S. Miyake, and K. Yagi (1977) Occurrence of 5-HT in chick retina. Experientia 33: 927-928.

Thomas, T. N., and D. A. Redburn (1979) 5-Hydroxytryptamine-a neurotransmitter of bovine retina. Exp. Eye Res. 28: $55-61$.

Walters, J. R., and R. H. Roth (1972) Effect of gamma-hydroxybutrate on dopamine and dopamine metabolites in the rat striatum. Biochem. Pharmacol. 21: 2111-2121.

Westerink, B. H. C., and J. Korf (1976) Effects of drugs on the formation of homovanillic acid in the rat retina. Eur. J. Pharmacol. 40: 175-178. 